\title{
A Novel Approach to Enhance QoS in Mobile WiMAX Networks
}

\author{
Charu Rawal \\ M.phil Scholar, \\ Maharishi Markandeshwar Institute of Computer \\ Technology \&Business Management \\ MMU, Mullana(Ambala) India
}

\author{
Rajeev Gupta \\ Assistant Professor, \\ Maharishi Markandeshwar Institute of Computer \\ Technology \&Business Management \\ MMU, Mullana(Ambala) India
}

\begin{abstract}
Wireless network is fast growing area. Wireless network has an ability to provide a good quality of service i.e voice, data, video conferencing etc. Different mobile generations are presented i.e $1 \mathrm{G}$ to $4 \mathrm{G}$. In this research paper, $4 \mathrm{G}$ technology is used. WiMAX is $4 \mathrm{G}$ technology. In this research work, create a WiMAX network and that network consist of 2 base stations, app configuration, profile configuration, WiMAX configuration and 16 mobile nodes. After creating a network check the quality of network i.e Jitter (sec) and delay (sec). In this research paper we conclude that when the speed of moving mobile node is increased we obtain the low delay and low jitter in network.
\end{abstract}

\section{Keywords}

QoS, WiMAX, UGS, Rtps, nrtPS,BE.

\section{INTRODUCTION}

Quality of Service (QoS) is the service that is used to deliver the different services to the mobile user in appropriate time. Some QoS properties of network are fixed as well as predefined with boundaries. [4] QoS is service that is used to measure the overall performance of network. Performance of network is measured to check the speed, accuracy and reliability. Different services are provided to different network traffic. Bandwidth, error ratio, queuing delay, jitter (delay variation) and throughput are a different service that comes under QoS. Extra additional $\mathrm{n} / \mathrm{w}$ resource is not created by QoS. Additional bandwidth is not created in the network.

\subsection{Wimax Architecture}

Subscriber station node and base station node are main component in WiMAX architecture. Subscriber station node sends the signal to the base station. Firstly create a connection and request for particular services. After creating a connection sends the packets from one node to other node.

\subsection{WIMAX QOS SERVICES}

WiMAX QoS standard has 4 different categories that is used for the prioritization of mobile node(traffic):

(1) Unsolicited Grant Service (UGS)

(2) Real-Time Polling Service (rtPS)

(3) Non-Real Time Polling Service (nrtPS)

(4) Best Effort (BE)

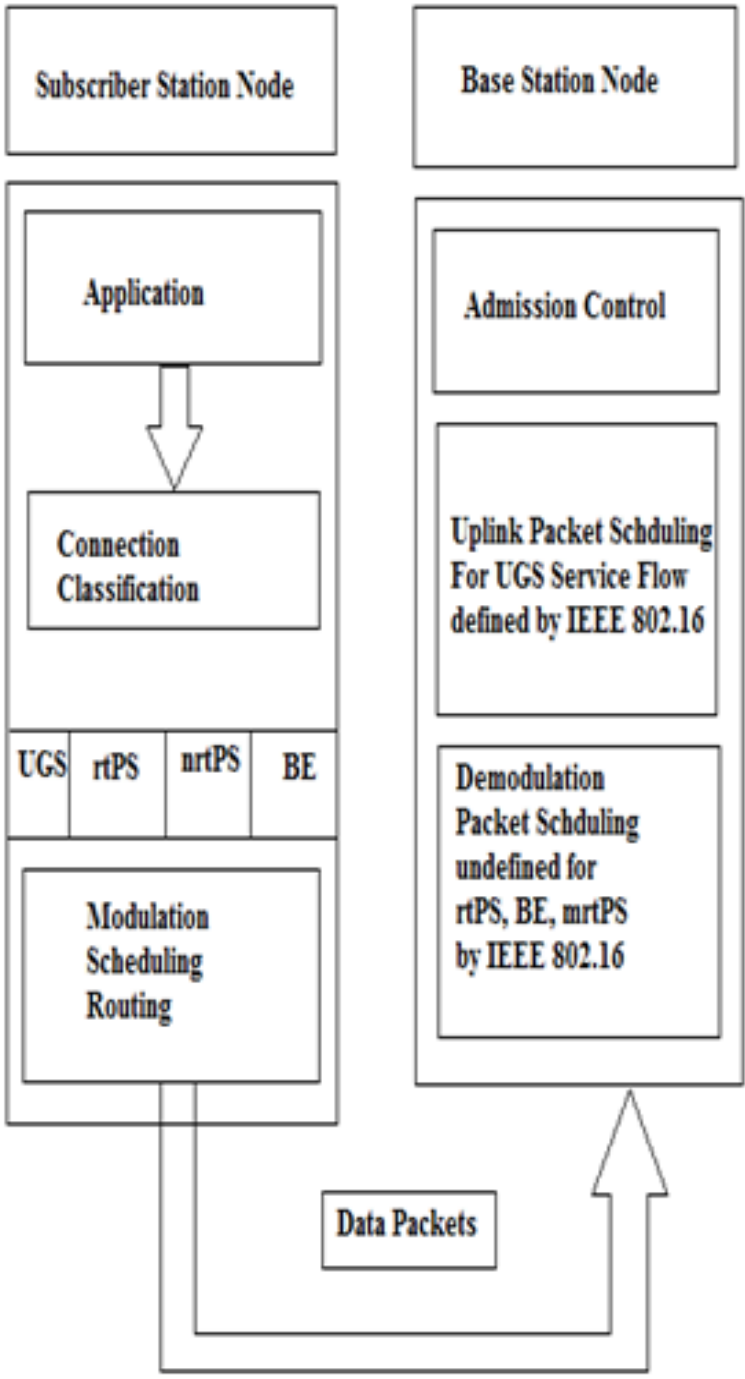

Fig. 1 Wimax Architecture 


\begin{tabular}{|c|c|}
\hline $\begin{array}{l}\text { Scheduling } \\
\text { Type }\end{array}$ & Polling Method \\
\hline UGS & $\begin{array}{l}\text { PM bits used to request the poll for bandwidth needs on } \\
\text { non UGS connection. }\end{array}$ \\
\hline ertPS & $\begin{array}{l}\text { Uses unicast polling. } \\
\text { BS offers unicast grant like unrequested UGS }\end{array}$ \\
\hline rtPS & Only allows unicast polling \\
\hline nrtPS & $\begin{array}{l}\text { May restrict service flow to unicast polling in } \\
\text { tansmission request policy }\end{array}$ \\
\hline BS & All forms of polling is allowed \\
\hline
\end{tabular}

Fig 2 QoS Classes

\section{RELATED WORK}

In [1] researchers proposed concept that analyze different QoS parameters. Analyze the parameter for WiMAX Network. This research helps in determining the overall performance of $4 \mathrm{G} \mathrm{n} / \mathrm{w}$ and parameters of $4 \mathrm{G} \mathrm{n} / \mathrm{w}$ is critical in nature. A very low value of Jitter, delay and packet loss) is achieved for 500 mobile users that exist in network. An AODV protocol helps in achieving the larger value of throughput. In [2] researchers proposed concept of performance of WiMAX (Worldwide Interoperability for Microwave Access) $n / w$ that check quality parameter for network. Using Multimedia technique, it provides a optimize result for BS (Base Station). This paper shows overall performance of quality of network that is based on particular location. In [3], researchers examine concept of WiMAX - based network and evaluate the performance for quality of service (QoS) using an idea of IEEE 802.16 technology. This research used a multiprocessor architecture organized by the interconnection of $\mathrm{n} / \mathrm{w}$. OPNET $17.5 \mathrm{TOOL}$ is used to create the architecture and to calculate performance criteria (i.e. throughput, delay and data dropped) that slightly concerned in network estimation. In [4] authors proposed a work to compare the QoS between UMTS 3G network and WiMAX 4G networks. Two network models were proposed has objective of studying a realistic approach: in UMTS model multiple users are placed in the network requesting some applications and then the network traffic measured and calculated. Regarding the WIMAX model scenario, where several users perform different services, enabling the analysis of network performance by measuring several parameters. In [11] researchers proposed a work to compare the QoS between UMTS $3 \mathrm{G}$ network and WiMAX $4 \mathrm{G}$ networks. Two network models were proposed has objective of studying a realistic approach: in UMTS model multiple users are placed in the network requesting some applications and then the network traffic measured and calculated. Regarding the WIMAX model scenario, where several users perform different services, enabling the analysis of network performance by measuring several parameters.

\section{PROPOSED WORK AND SIMULATION}

Create a WiMAX n/w with the help of OPNET TOOL 17.5. This network checks quality of service. The WiMAX network should consists of base stations, mobile nodes, application configuration, profile configuration and WiMAX configuration. Application configuration profile configuration and WiMAX configuration are used to set the properties of network

This network shown in figure 3 consists of 2 base stations, 1 profile configuration, 1application configuration, 1 WiMAX configuration and 16 mobile nodes.

Some of the quality parameters like jitter and delay is checked in WiMAX network.

WiMAX network is shows in the given below figure 3 . TheWiMAX network consist of App config. , Profile config and WiMAX config.

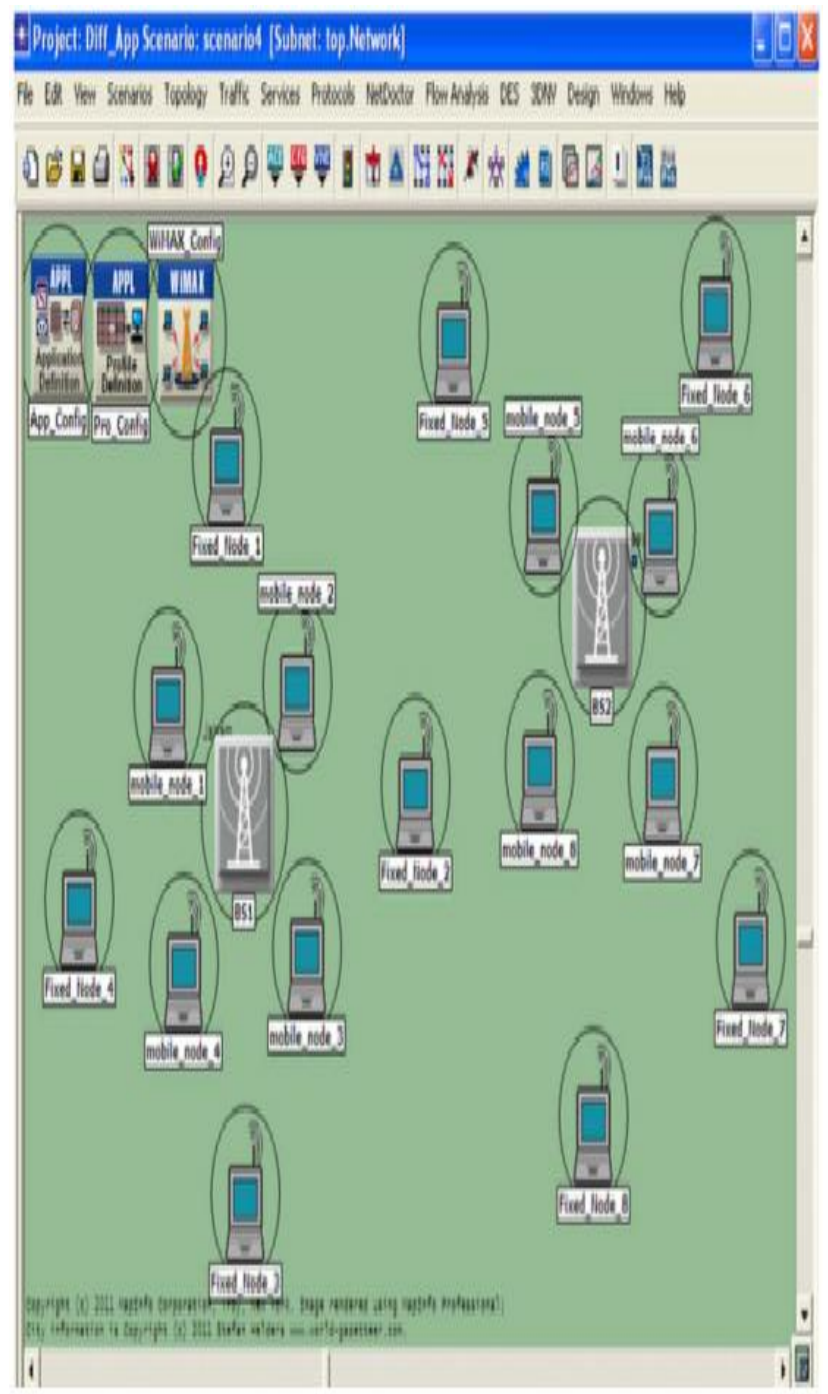

Fig 3 WiMAX Architecture

Some of parameters are given below which is used for simulation. 


\begin{tabular}{|c|c|}
\hline Parameders & Value \\
\hline Tranmision power & 0.005 \\
\hline Examined Ruting Protool & AODV \\
\hline MAC Type & EEE 302.11 DCF, EEE 802.16 \\
\hline Number of $n$ des & 95 \\
\hline Simulation Area & $150 \mathrm{x} 1500$ Square meter: \\
\hline Mobility Sped & $20,60,10 \mathrm{bow} / \mathrm{Hour}(\mathrm{mm})$ \\
\hline Trajectory Inf. & $\begin{array}{c}\text { MAETWINX mobility } \\
\text { gcemario, Vector }\end{array}$ \\
\hline Reception pwer theshold & $.95 \mathrm{dBm}$ \\
\hline Data rate & 11Mbp: \\
\hline Mobility Model & Random Way pint \\
\hline Buffer size & 236000bits \\
\hline FragmentationThreabold (bytes) & 1024 \\
\hline Traffic & Onde VOP \\
\hline Simulation & $\begin{array}{l}500000 \text { exents Based on Kenel } \\
\text { type preference }\end{array}$ \\
\hline Simulation Time & $30 \mathrm{~min}$ \\
\hline Seed & 128 \\
\hline Update Interval & 500000 \\
\hline Values per Statistic & 100 \\
\hline
\end{tabular}

Fig 4 Simulation Table

\subsection{Delay (sec)}

Delay parameter is checked in WiMAX network. Delay is basically refers to time needed for a packet which is to be travelled from corner to corner of $\mathrm{n} / \mathrm{w}$ from one moving node to another moving node in the network. The delay typically measured in fractions of seconds. When rate of moving node is greater than before then delay is degraded as shown in given below figure. This results shows that degraded performance of network.

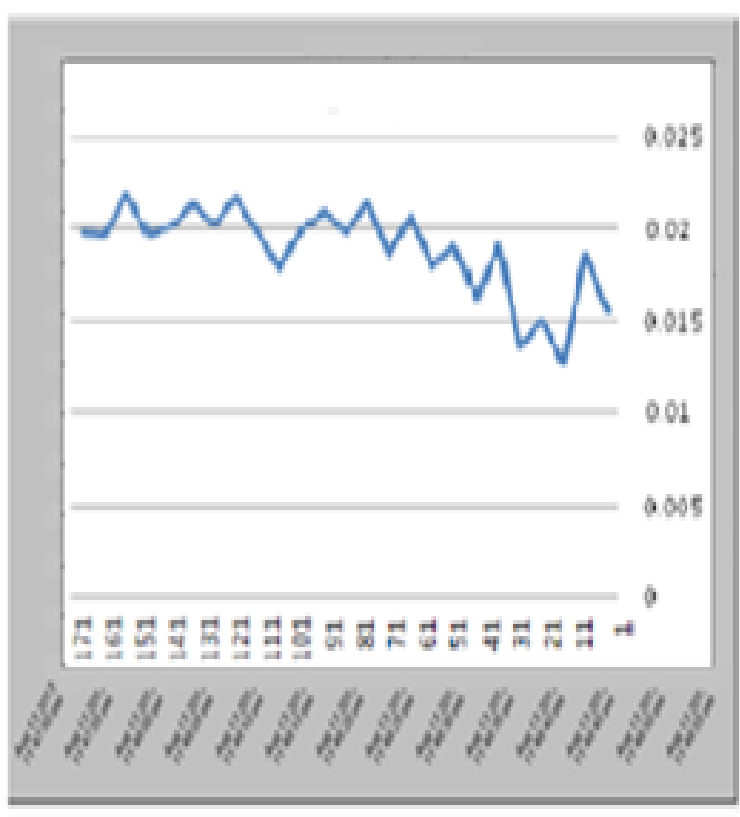

Fig 5 WiMAX Delay (Sec)

\subsection{Jitter (Sec)}

Jitter is basically a form of latency. Jitter is measured in the variability over time of packet latency across a network.

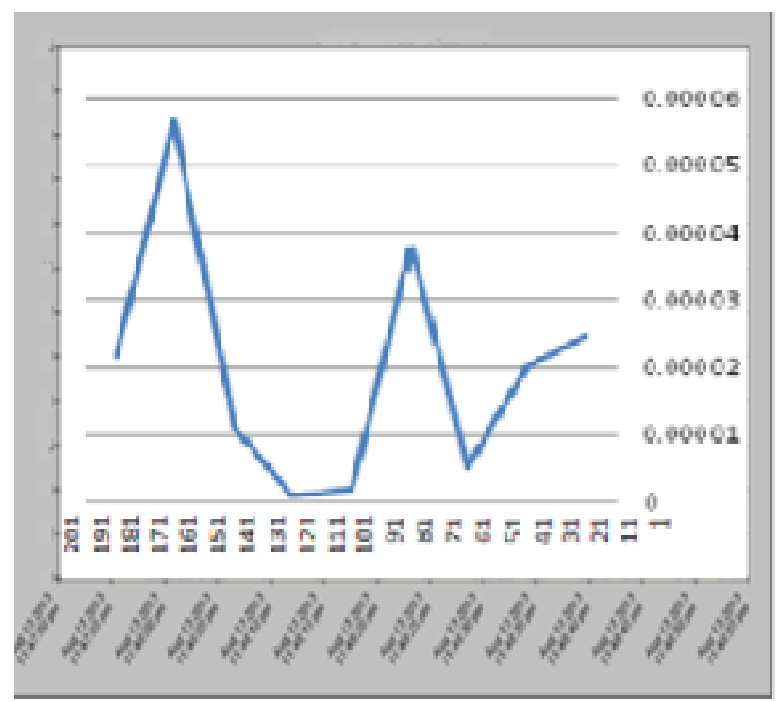

Fig 6 WiMAX Throughput (packet/sec)

\section{CONCLUSION AND FUTURE WORK}

This research paper is evaluating the performance of WiMAX network under QOS condition. In this research paper jitter and delay of the network is checked. Jitter per second and Delay per second is checked. Implemented network, practically verify the performance of networks. With OPNET TOOL, enlarge the region of network to check the performance of various Qos parameters. In this network perform a handover task after defining a trajectory into the network. Using better Qos, better handover results can be obtained. 


\section{REFERENCES}

[1] Vikram Mehta and Dr. Neena Gupta, Performance Analysis of QoS Parameters for Wimax Networks in IJEIT, 2012.

[2] Rakesh Kumar Jha, Idris Z. Bholebawa, Location Based Performance of WiMAX Network for QoS with Optimal Base Stations (BS) in SciRp, 2011.

[3] Ahmed Hassan M. Hassan, Elrasheed Ismail M. ZAYID, PERFORMANCE EVALUATION OF QOS IN WIMAX NETWORK in CAD, 2015.

[4] Amit Kumar, Dr. Yunfei Liu ,Dr. Jyotsna Sengupta, Divya, "Evolution of Mobile Wireless Communication Networks 1G to 4G", International Journal of Electronics \& Communication Technology, IJECT Vol. 1, Issue 1, Dece- mber 2010.

[5] Dina Mohammed Hassan Al-Zubair, Amen Babikr Abdal-Nabi2 QoS Comparison between UMTS 3G Network and WIMAX 4G network in IJSR, 2015.

[6] OPNET Inc., "OPNET Modeler", OPNET University program, 2012
[7] Bo Li and Yang Qin and Chor Ping Low and Choon Lim Gwee, "A Survey on Mobile WiMAX [Wireless Broadband Access]", IEEE Communications Magazine, P.P. 70-75, 12(45), December 2007

[8] ZAYID, ELRASHEED I. M. and AKAY, M. FATIH, 2012c. "Predicting the performance measures of a message-passing multiprocessor architecture using artificial neural networks". Neural Comput \& Applic, 21(8)

[9] CULLER, D., SINGH J. P. and GUPTA A., "Parallel Computer Architecture: Hardware/Software Approach", 4th addition, Morgan Kaufmann Publishers, San Francisco, USA, 1999.

[10] Bo Li and Yang Qin and Chor Ping Low and Choon Lim Gwee, "A Survey on Mobile WiMAX [Wireless Broadband Access]", IEEE Communications Magazine, P.P. 70-75, 12(45), December 2007

[11] Dina Mohammed Hassan Al-Zubair, Amen Babikr Abdal-Nabi2 QoS Comparison between UMTS 3G Network and WIMAX 4G network in IJSR, 2015. 